\title{
The Real Relationship Between Organizational Culture and Organizational Learning
}

\author{
Fumie ANDO \\ School of Business Administration, Nanzan University \\ E-mail:fumiea@nanzan-u.ac.jp
}

\begin{abstract}
Many recent efforts argue that organizational culture is the key of excellent organizational learning. This article discusses the "real" relationship between organizational culture and organizational learning. By analyzing questionnaire survey data, it was found that: (1) organizational culture merely had indirect influences over organizational learning, however, (2) there was a much more important factor in learning process, that is, a "Navigation Map in the organization." The Navigation Map forming is facilitated by the desirable organizational culture: especially the paradoxical culture which succeeds to be balanced between opposite features simultaneously.
\end{abstract}

Keywords: organizational learning, navigation map in the organization, paradoxical culture

\section{Theoretical Background}

During the 1990s, the study of organizational learning has become one of the hottest topics among researchers and practitioners (Crossan \& Guatto, 1996; Easterby-Smith, 1997). Successful organizational learning can lead organization to the competitive advantage by acquiring new and necessary knowledge, competences and values. Many researchers have examined the key elements or factors in realizing successful organizational learning processes.

One of the essential factors is organizational culture. A famous researcher in organizational culture, Schein (1984) argues that organizational culture is the pattern of basic assumptions that organization has developed in learning: Therefore it can give effects to the quality of organizational learning. When organization has unsuitable basic 
assumptions-Schein called the situations "anxiety-avoidance situations"-it is difficult to realize the radical learning which can lead innovation. By contrast, when organization is in the "positive problem-solving situations," the possibility of big success will increase.

Researchers of organizational learning also accept that there is a close relationship between organizational learning and organizational culture. Argyris \& Schon $(1978,1996)$ divide organizational learning processes into two types. One is single-loop learning that organization detects and corrects errors so as to maintain the existed theory-in-use. The other is double-loop learning that organization inquires into the theory-in-use itself. According to them, single-loop learning tends to occur under the O-I system, and double-loop learning tends to appear under the O-II system. O-I system is very similar to Schein's anxiety-avoidance situation and O-II system is very close to his positive problem-solving situation. Nevis, DiBella and Gould (1995) also point out that open and supportive climate for trying new things is one of ten facilitating factors in the successful learning organization. Among academics and practitioners, it seems to reach the consensus that the better organizational culture will lead organization to more desirable or higher-level learning processes.

Now, we must consider whether the relationship between culture and learning is direct or not. Surely, the better organizational culture facilitates active organizational learning. But we know that organizational learning is based on individual learning by organizational member and that each member's learning level is various even if all members are under the same organizational culture. Otherwise, there are some cases that organizational members begin to behave actively, though organizational culture does not seem to change. These disproofs suggest that there is no direct relationship between culture and learning.

Hypothesis 1: There will be no direct relationship between organizational culture and organizational learning.

On the other hand, we cannot ignore the accumulated research results that organizational culture is the key factor in organizational learning. Then, this paper focuses on the third but important element that connects culture and learning. For example, Senge (1990) insists that people actively and energetically do learning when there is a force called "creative tension" which is generated by keeping both a personal vision and a clear picture of current reality. Nevis et al. (1995) indicate that having shared perception of a gap between actual and desired state of performance is important for the learning organization. People can feel or understand such tensions and gaps through both self-reflection and open communication with other members (Argyris, 1994; Argyris \& Schon, 1978; Nevis et al., 1995; Senge, 1990). In other words, people can do it better under the better organizational culture.

Hypothesis 2: There will be the third element that connects organizational culture and 
organizational learning. It will be positive association with both organizational culture and organizational learning processes.

In the academic interviews the author had before, corporate managers often said that they needed the person who understood both corporate vision and his or her actual state as well: who had his or her own "map" which let the person know where to go or what to do. By using managers' words above, this paper called the third element "Navigation Map in the organization" (Ando, 2001). Like a car navigation system, each Navigation Map shows each organizational member the information that you are here, that your goal is there, and that this is the path you can reach that goal.

\section{Method and Measures}

To test these hypotheses, this paper analyzed questionnaire survey data statistically. The survey which is called Japan Productivity Center survey 99 (JPC 99) was conducted to cover four Japanese companies from September to October 1999. JPC surveys were mainly conducted by Professor Nobuo Takahashi of University of Tokyo almost every year. It is he who has written all items of this questionnaire survey. The questionnaires were sent to 881 employees in total and 790 respondents send it back. A usable response rate was 89.9 percent.

The degree that organization has desirable organizational culture was measured with three items below:

C1: Is the atmosphere one which welcomes challenging new jobs?

C2: Is adopting the corporate culture more important than developing your own individuality?

C3: Is avoiding failure considered more important than improving performance through trial and error?

Otherwise, the degree that each organizational member actively does learning was measured with three items below:

L1: Do you constantly seek improved way of doing your jobs better than the others?

L2: Do you do your job in the way you want regardless of the way it was done in the past?

L3: Do you go out of your way to do new jobs before they are assigned to some sections?

In order to measure the degree that each organizational member forms his or her Navigation Map, this paper also used three items below:

M1: As you work on your job, do you continually keep in mind the policies of top management? M2: Are you able to see the desirable shape which your company will take in the 21 st century?

M3: Are your job targets clearly specified by your superiors?

The responses were recorded on two-point. If an answer is yes, it was rated at one. On the other hand, if an answer is no, it was rated at zero. As C2 and $\mathrm{C} 3$ were reverse items, yes-answer was rated at zero and no-answer was rated at one as for these two items.

At first, these nine items were assessed by factor analysis with orthogonal varimax rotation. As shown in Table 1, this paper can produce a 
Table 1. Results of Factor Analysis for Culture, Learning and Navigation Map

\begin{tabular}{lccc}
\hline & Factor 1 (Culture: IDC) & Factor 2 (Learning: IAL) & Factor 3 (Navigation Map: INM) \\
\hline C1 & $\mathbf{0 . 7 3 8}$ & -0.007 & 0.226 \\
C2 & $\mathbf{0 . 7 7 4}$ & 0.040 & 0.018 \\
C3 & $\mathbf{0 . 7 1 0}$ & 0.128 & -0.072 \\
L1 & 0.017 & $\mathbf{0 . 7 3 4}$ & 0.165 \\
L2 & -0.049 & $\mathbf{0 . 8 1 8}$ & -0.060 \\
L3 & 0.193 & $\mathbf{0 . 5 3 0}$ & 0.184 \\
M1 & -0.026 & 0.144 & $\mathbf{0 . 7 7 3}$ \\
M2 & 0.008 & 0.162 & $\mathbf{0 . 7 3 8}$ \\
M3 & 0.351 & -0.055 & $\mathbf{0 . 4 7 7}$ \\
\hline
\end{tabular}

* The three factors together explain $54 \%$ of the variance.

* Loadings over .45 are shown.

Table 2. Pearson Product Moment Correlations and Descriptive Statistics

\begin{tabular}{lcccc}
\hline Variables & Mean & s.d. & 1 & 2 \\
\hline 1. IDC (Culture) & 0.84 & 0.65 & ------ & ------ \\
2. IAL (Learning) & 1.21 & 0.55 & $0.117^{* *}$ & ------ \\
\cline { 4 - 5 } 3. INM (Navigation Map) & 1.08 & 0.58 & $0.194 * * *$ & $0.246^{* * *}$ \\
\hline & & & $(* p<0.05, * * p<0.01, * * * p<0.001)$
\end{tabular}

three-factor solution. This solution is consistent with the idea that is proposed as three measurements above. Then, three items that consist of each of the three factors (organizational culture, learning activity in the organization and Navigation Map forming) were assessed with principal component analysis by turns. In all three factors, each eigenvalue of the first principle factor is over 1 . Therefore, this paper called these three first principle factors "Index of Desirable Culture (IDC)," "Index of Actively Learning (IAL) " and "Index of Navigation Map (INM)" by turns. In testing hypotheses above, this paper used these three indexes.

\section{Results}

Table 2 contains the Pearson product moment correlation matrix and descriptive statistics for the indexes. The correlation between IDC and IAL (0.117) is both positive and significant at the 0.01-level. That is, desirable organizational culture has a positive relationship with organizational learning.

Although the result is consistent with past studies on both organizational learning and organizational culture, the correlation coefficient between them is not so high as have been expected. Rather, Table 2 shows that the Navigation Map Forming has much closer and stronger relationship with organizational learning. In spite of this result, past research has insisted that culture is a key of successful organizational learning. To investigate the causes of this inconsistency, these three factors were 
Figure 1. Result of Path Analysis of Three Factors

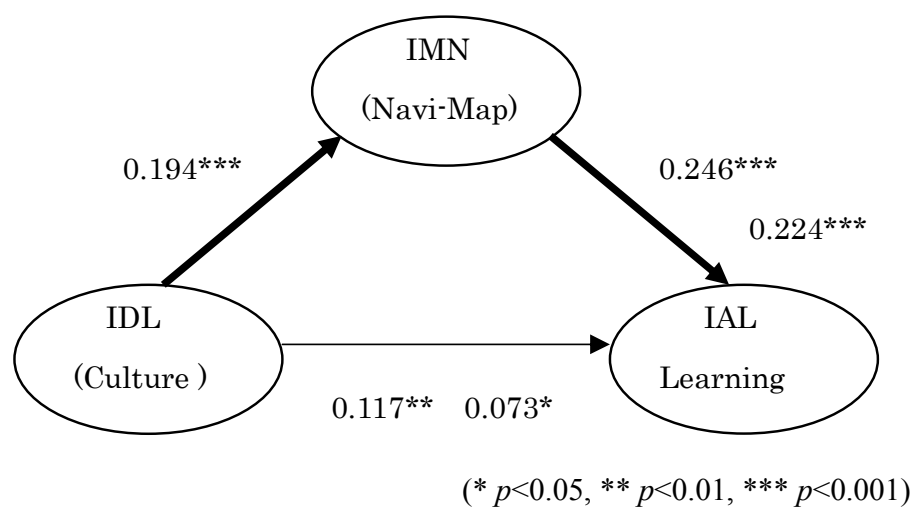

assessed by path analysis.

As a result of path analysis, the outcome was surprising. As shown in Figure 1, the direct path from IDC to IAL is not significant at 0.01-level though the correlation between them is significant. On the other hand, the path from IDC to IAL by way of INM is still significant at $0.01-$ level. This result shows that organizational culture has an indirect relationship rather than a direct relationship with organizational learning processes. It also shows that, as expected, much more important factor of organizational learning is Navigation Map formed by organizational members. In sum, the desirable organizational culture facilitates organizational members to form each Navigation Map, and then, the members who have fully-forming Navigation Map can learn actively in the organization. Hypotheses 1 and 2 were supported.

\section{Paradoxical Culture for Navigation}

\section{Map Forming}

As stated above, the desirable organizational culture has an influence on Navigation Map Forming. In this paper, the desirable organizational culture means Schein's positive problem-solving situation, the atmosphere which welcomes challenging new jobs, the organization which encourages its members to develop each personality, and so on. However, when considering the desirable organizational culture from another aspect, we may say that it is the paradoxical culture. The paradoxical culture is defined as being successful in fulfilling apparently opposite features simultaneously, for example, cooperation and competition.

Both cooperative and competitive culture are useful to actively do learning in the organization. Argyris \& Schon (1978) point that win-lose game between organizational members will be serious obstacles for successful organizational learning. It means that non-cooperative culture has bad effects 
Table 3. The Result of Response to C4 and C5 and Their Coefficients

\begin{tabular}{|c|c|c|c|c|c|c|}
\hline & \multicolumn{2}{|c|}{ Response } & \multicolumn{4}{|c|}{ Correlation coefficient } \\
\hline & Yes & No & IDC & IAL & IMN & $\mathrm{C} 4$ \\
\hline $\begin{array}{l}\mathrm{C} 4 \\
\text { (cooperation) }\end{array}$ & $\begin{array}{c}605 \\
(76.9 \%)\end{array}$ & $\begin{array}{c}182 \\
(23.1 \%)\end{array}$ & $0.120 * * *$ & $0.070+$ & $0.189 * * *$ & ------ \\
\hline $\begin{array}{l}\text { C5 } \\
\text { (competition) }\end{array}$ & $\begin{array}{c}128 \\
(16.3 \%)\end{array}$ & $\begin{array}{c}659 \\
(83.7 \%)\end{array}$ & $0.193 * * *$ & $0.102 * *$ & $0.141 * * *$ & $0.095 * *$ \\
\hline
\end{tabular}

on organizational learning processes. On the other hand, they mention that moderate competitive culture is essential to higher-level learning. Nevis et al. (1995) also state very similar ideas.

Although cooperative culture and competition culture are apparently opposite to each other, some past researches show that cooperative behavior is compatible with competitive one. According to Axelrod (1984), when there is a "nice" relationship where one member or group continues to compete with others while keeping their cooperation, both of them can get higher scores.

Taken together, the compatible culture will be useful for successful organizational learning processes. Moreover, it will be much useful for Navigation Map Forming because the desirable organizational culture has an effect on organizational learning by way of members' Navigation Map. In order to investigate the relationship between the paradoxical culture and Navigation Map, another two items on organizational culture, exactly stating, workplace culture, were used.

C4: Is there a strong feeling of partnership between employees at your workplace? (Yes/No)
C5: Is there a strong feeling of competition between employees at your workplace? (Yes/No)

Table 3 shows the result of responses to both questions and the Pearson product moment correlation coefficients between these two items and three factors. As mentioned above, JPC 99 survey data was gathered from Japanese companies. Therefore, we can consider that Table 3 shows the tendency of Japanese firms' answers to some extent. Yes-respondents to $\mathrm{C} 4$ (cooperation) is over $70 \%$. On the contrary, yes-respondents to C5 (competition) is less than $20 \%$. These results correspond with image of Japanese firms. Table 3 also shows that both $\mathrm{C} 4$ and $\mathrm{C} 5$ are almost correlated with three factors: IDC, IAL and IMN. As expected, the correlation coefficient between INM and C4 (C5) is higher than the one between IAL and $\mathrm{C} 4$ (C5). Because $\mathrm{C} 4$ and $\mathrm{C} 5$ are positive correlation with IDC, they may be alternative measurements of IDC.

For the purpose of investigating the effects of paradoxical culture on Navigation Map Forming, this paper divided respondents into four groups according to responses to C4 and C5: (1) C4-Yes and C5-Yes, (2) C4-No and C5-Yes, (3) C4-Yes and 
Figure 2. The Comparison of INM \& IAL Score Between Four Groups

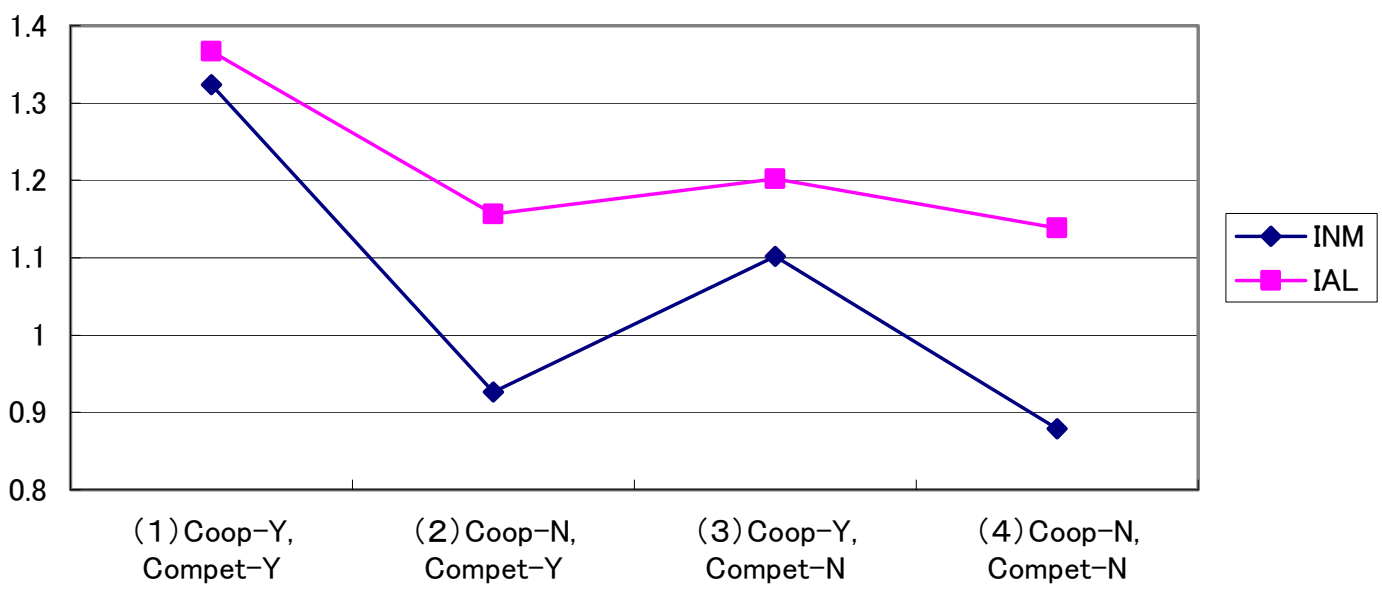

C5-No, and (4) C4-No and C5-No. The number of each group is $110(14.0 \%), 18(2.3 \%), 495(62.9 \%)$ and $164(20.8 \%)$ samples by turns. The number of the third group is the largest. It seems that sample firms generally have cooperative culture without competition. The second largest group is the one that have neither cooperative culture nor competitive culture.

Each IMN score average of four groups was calculated and compared. It is shown in Figure 2. The highest-score group is the first one that consists of the respondents who have both cooperative and competitive culture simultaneously. This paper called the first group "paradoxical culture group." On the other hand, the third and the fourth groups that account for over $80 \%$ of JPC 99 survey data could not get high scores. Of the three groups except the paradoxical culture group, the third group, which has only cooperative culture, is the highest. However, the result of analyses of variance with general linear models procedure (GLM) shows that there is no statistically significant difference among three groups except the paradoxical culture group. It is between the paradoxical culture group and the other ones that there is a significant difference $(F=14.29)$ at 0.01-level.

As shown in Figure 2, the paradoxical culture group succeeds to get the highest score of IAL as well. As the effect of organizational culture on organizational learning is indirect, it is weak in comparison with the case of IMN. These results illustrate that the existence of paradoxical culture can facilitate organizational members to form their Navigation Map, and can improve organizational learning processes actively as a result of it.

\section{Discussion}

The main aim of this paper is to discuss the "real" relationship between organizational culture and organizational learning. And the principal 
implications of this study are that (1) organizational culture has not a direct but an indirect influence over organizational learning processes against the consensus of past studies, and that (2) there is a much more important factor for learning processes, which is named "Navigation Map in the organization." All the results here show that desirable organizational culture has an effect on organizational learning processes by way of Navigation Map.

In this paper, at first, the desirable culture meant just the one which has desirable aspects according to past studies on organizational learning; for example, a challenging mind, an open-mind, and a positive atmosphere of problem-solving. However, in the course of analysis and consideration, this paper noticed that the paradox was also an important element for desirable culture. Actually, the results of analyses illustrate that the paradoxical culture plays an important role to form Navigation Map and to improve learning activities in the organization.

This paper focused on the culture which has both cooperative and competitive aspects simultaneously as the paradoxical culture. We know that there will be another various combinations of paradoxical aspects. As long as much more combinations are not tested, we can not generalize the positive relationship between paradoxical culture and Navigation Map. However, there is a good prospect that relationship between them is supported. According to Fiol (1994), successful organizational learning processes need to manage the apparently paradoxical features: consensus and diversity. Furthermore, studies on charismatic leadership also state that charismatic leader tends to have some paradoxical characteristics. For example, they are dreamers and realists, or they are daring and prudent persons (Nadler \& Tushman, 1989). Further study of this issue will be needed.

\section{Acknowledgement}

This research was funded by Pache I-A of Nanzan University. I would like to thank Japan Productivity Center and Prof. Nobuo Takahashi of University of Tokyo for giving me precious data.

\section{References}

Ando, F. (2001). Soshiki gakushu to soshikinai chizu [Theories of organizational learning and navigation map in the organization]. Tokyo: Hakuto-Shobo. (In Japanese)

Argyris, C. (1994). Good communication that blocks learning. Harvard Business Review, (1994, July-August), 77-85.

Argyris, C., \& Schon, D. A. (1978). Organizational learning: A theory of action perspective. Reading, MA: Addison-Wesley.

Argyris, C., \& Schon, D. A. (1996). Organizational learning: Theory, method, and practice. Reading, MA: Addison-Wesley.

Axelrod, R. (1984). The evolution of cooperation. New York: Basic Books.

Crossan, M. M., \& Guatto, T. (1996). Organizational learning research profile. Journal of 


\section{Organizational Culture and Organizational Learning}

Organizational Change, 9(1), 107-112.

Easterby-Smith, M. (1997). Disciplines of organizational learning: Contributions and critiques. Human Relations, 50(9), 1085-1113.

Fiol, C. M. (1994). Consensus, diversity and learning in organizations. Organization Science, 5(3), 403-420.

Nadler, D. A., \& Tushman, M. L. (1989). Beyond the charismatic leader: Leadership and organizational change. California Management Review, 32(2), 77-97.
Nevis, E. C., DiBella, A. J., \& Gould, J. M. (1995).

Understanding organizations as learning systems. Sloan Management Review, (1995, Winter), 73-85.

Schein, E. H. (1984). Coming to a new awareness of organizational culture. Sloan Management Review, (1995, Winter), 3-16.

Senge, P. M. (1990). The fifth discipline. New York: Doubleday/Currency.

(Received June 30, 2002; accepted July 8, 2002) 


\section{Ando}

